\title{
MASTER
}

M. $309 \%$

ORNL/TM-6904

\section{Dose Rates from Induced Activity in the TFTR Test Cell}

\author{
R. G. Alsmiller, Jr. \\ J. Barish \\ R. T. Santoro \\ R. A. Lillie \\ J. M. Barnes \\ M. M. H. Ragheb
}

\section{OAK RIDGE NATIONAL LABORATORY} OPERATED BY UNION CARBIDE CORPORATION - FOR THE DEPARTMENT OF ENERGY 


\section{DISCLAIMER}

This report was prepared as an account of work sponsored by an agency of the United States Government. Neither the United States Government nor any agency Thereof, nor any of their employees, makes any warranty, express or implied, or assumes any legal liability or responsibility for the accuracy, completeness, or usefulness of any information, apparatus, product, or process disclosed, or represents that its use would not infringe privately owned rights. Reference herein to any specific commercial product, process, or service by trade name, trademark, manufacturer, or otherwise does not necessarily constitute or imply its endorsement, recommendation, or favoring by the United States Government or any agency thereof. The views and opinions of authors expressed herein do not necessarily state or reflect those of the United States Government or any agency thereof. 


\section{DISCLAIMER}

Portions of this document may be illegible in electronic image products. Images are produced from the best available original document. 


\section{Printed in the United States of America. Available from National Technical Information Service \\ U.S. Department of Commerce \\ 5285 Port Royal Road, Springfield, Virginia 22161}

Price: Printed Copy $\$ 4.50$; Microfiche $\$ 3.00$

This report was prepared as an account of work sponsored by an agency of the United States Government. Neither the United States Government nor any agency thereof, nor any of their employees, contractors, subcontractors, or their employees, makes any warranty, express or implied, nor assumes any legal liability or responsibility for any third party's use or the results of such use of any information, apparatus, product or process disclosed in this report, nor represents that its use by such third party would not infringe privately owned rights. 
ORNL/TM-6904

Dist. Category UC-20d

(Fusion Systems)

Contract No. W-7405-eng-26

Engineering Physics Division

\section{DOSE RATES FROM INDUCED ACTIVITY IN THE TFTR TEST CELL *}

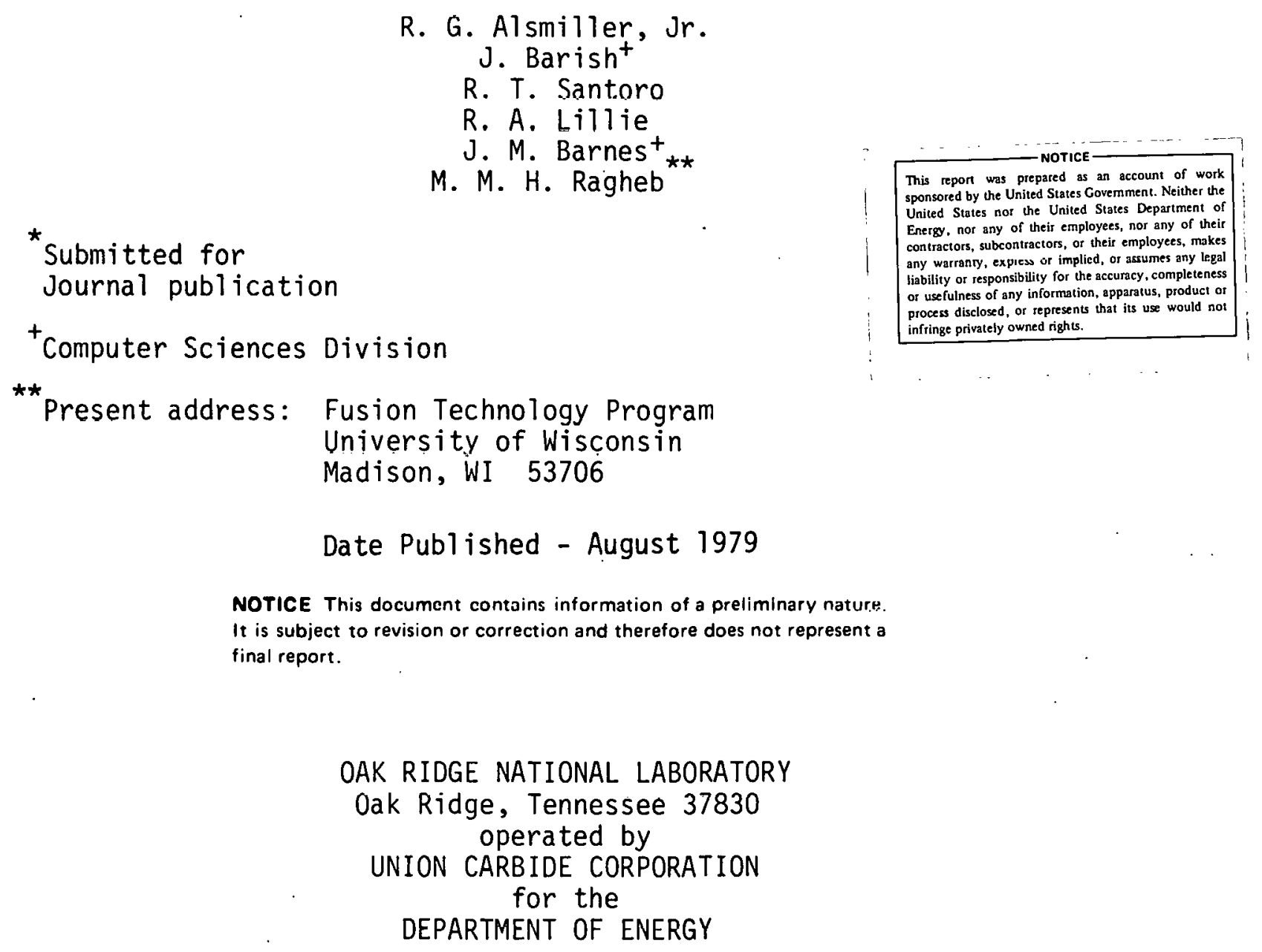


THIS PAGE

WAS INTENTIONALLY

LEFT BLANK 


\section{ACKNOWLEDGEMENTS}

Thanks are due to R. Little, G. Sheffield, K. Young, H. J. Howe, Jr. and Long-Poe Ku of the Princeton Plasma Physics Laboratory for helpful discussions during the course of this work. 
THIS PAGE

WAS INTENTIONALLY

LEFT BLANK 
ABSTRACT

Calculated dose rates in the TFTR test cell from induced activity have been obtained. The dose rates for the case of no neutral beam injector and when a neutral beam injector (with the resultant large penetration through the primary shield) is present are given separately. The photon transport calculations are carried out using Monte Carlo techniques since this greatly facilitates the consideration of different pulse sequences and times after reactor shutdown. Dose rates are given for several different $D-T$ pulse sequences and for a variety of times after the reactor is turned off. At a few positions in the test cell the contribution to the dose rates from individual residual nuclei are also presented. In general, it is found that the presence of the shielded neutral beam injector does not have a large effect on the dose rates in the test cell. 


\section{INTRODUCTION}

The Tokamak Fusion Test Reactor (TFTR) that will operate on a D-T cycle is being constructed at Princeton University. ${ }^{1}$ The plasma in this reactor will be heated by the injection of several high-energy neutral deuterium beams and this will necessitate the presence of several large penetrations through the primary shield around the reactor. The neutrons and photons that stream through these large penetrations cause major design problems. In two previous papers ${ }^{2,3}$, calculated results of the effects of one of these penetrations on the heating rate in the cryopanels of a neutral beam injector and on the shielding requirements of the test cell were presented. In this paper the dose rates from induced activity in the TFTR test cell are given. The results given here differ from those presented previously by R. A. Friedenberg ${ }^{4}$ in that the effects of a neutral beam injector and the large penetration through the primary shield needed to accommodate neutral beam injection are taken into account. Furthermore, the calculational procedure used to obtain the results presented here differ from those of Freidenberg in that the photon transport calculations are carried out using Monte Carlo methods rather than discrete ordinates methods. The use of Monte Carlo methods allows all of the time-dependent calculations to be carried out after the photon transport calculations and greatly facilitates the consideration of a large number of $D-T$ pulse sequences and times after reactor shutdown. 5

In Section 2.A the geometries used in the calculations are briefly described. These geometries are the same as those used in Ref. 3 and, in fact, the neutron fluxes per unit energy used here are those calculated in Ref. 3. In Section 2.B the calculational procedure is discussed and 
the advantages of using Monte Carlo methods to carry out the photon transport calculations are indicated. In Section 2.C the sources of the data used in the calculations are given and a few additional details of the calculations are presented. In Section 3 the results are presented and discussed.

\section{METHOD OF CALCULATION}

\section{A Geometry}

In Fig. 1 a very schematic diagram of the TFTR test cell with a single neutral beam injector is given. It should be noted that the TFTR neutral beam injection is tangential to the plasma and not radial as the schematic diagram seems to indicate. The diagram is to scale, so all dimensions may be obtained from the scales given on the ordinate and the abscissa. In the diagram the polodial field coils (inside of the igloo) are not shown but they were included in the calculations. The toroidal field coils, also not shown, were not included in the calculations. Also, it should be noted that the floor of the test cell is not included in the calculations reported here. A detailed drawing of the TFTR test cell will be found in Ref. 1 and additional schematic diagrams of the geometry used in the calculations reported in this paper will be found in Refs. 2 and 3 . In fact, the neutron fluxes per unit energy used here are those calculated in Ref. 3, so more information than that given below on the calculation of these neutron fluxes will be found in Ref. 3 .

The composition of many of the injector components are shown in Fig. 1.

\footnotetext{
"The effect of the presence of the toroidal field coils when there are no penetrations in the igloo was considered by Friedenberg ${ }^{4}$ and was not found to be substantial.
} 


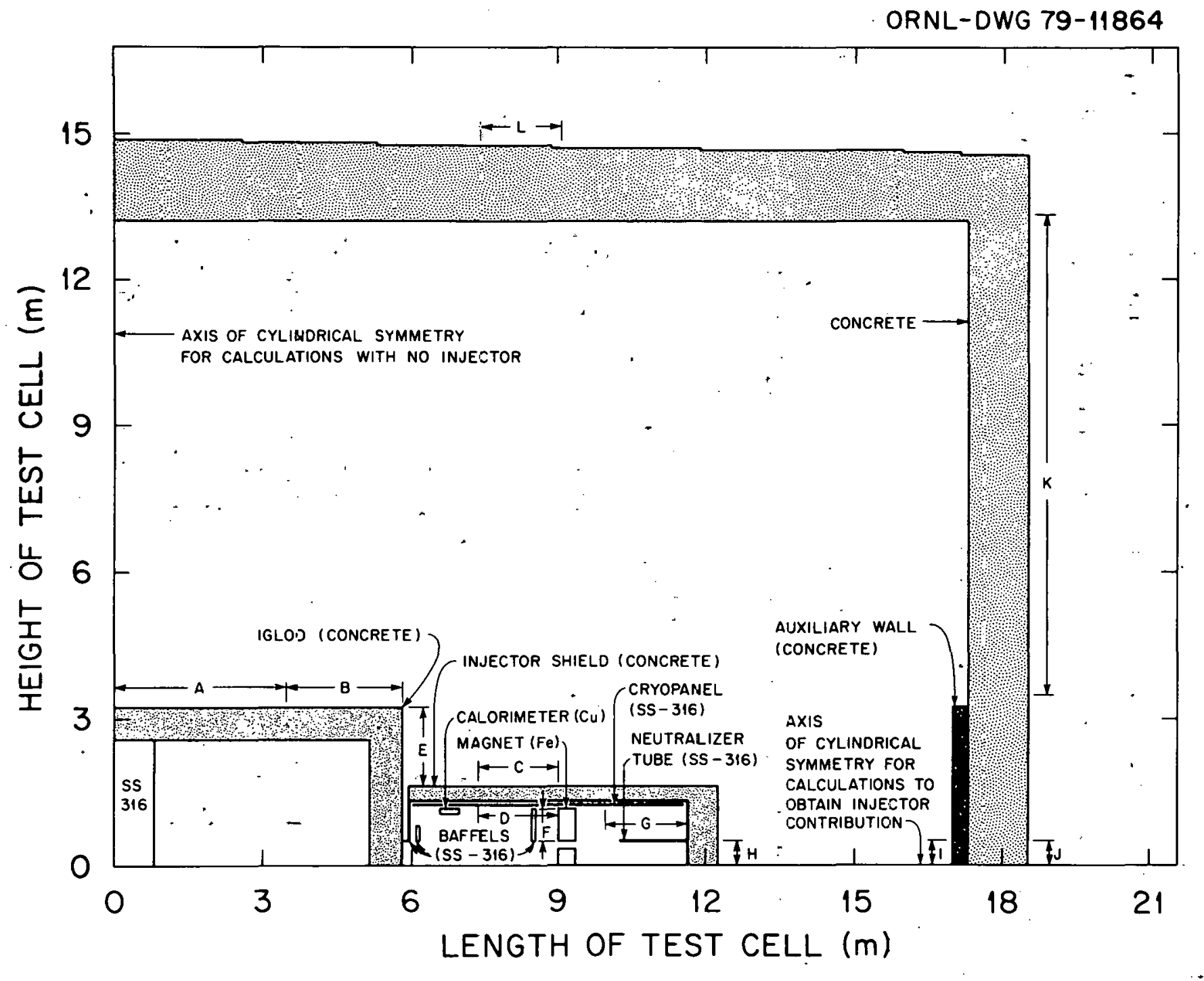

Fig. 1. Schematic diagram of TFTR test cell. The diagram is drawn to scale. Compositions of the various concretes are given in Table 1 . 
The poloidal field coils that are not shown were assumed to be copper. The post at the center of the igloo was assumed to be stainless steel of type 316 having a reduced density of $.25 \rho_{S S}$ to account for the tubular structure. The composition of the three types of concrete used in Fig. 1 is given in Table 1. The test cell walls and roof are made of nonborated concrete, but the inner surfaces of the test cell wall and roof are coated with borated plaster having a thickness of $0.01 \mathrm{~m}$.

\section{TABLE 1}

CONCRETE COMPOSITIONS USED IN THE CALCULATIONS

\begin{tabular}{llcl}
\hline & \multicolumn{3}{c}{$\begin{array}{c}\text { Concrete Composition } \\
\text { (Atoms/cm Barn) }\end{array}$} \\
\cline { 2 - 4 } Element & $\begin{array}{c}\text { Used for Ig100 } \\
\text { and Injector } \\
\text { Shield }\end{array}$ & $\begin{array}{c}\text { Used for } \\
\text { Auxiliary } \\
\text { Wall }\end{array}$ & $\begin{array}{c}\text { Used for Test } \\
\text { Cel1 Wal1 } \\
\text { and Roof }\end{array}$ \\
\hline $\mathrm{H}$ & $8.246 \cdot 10^{-3}$ & $7.830 \cdot 10^{-3}$ & $7.830 \cdot 10^{-3}$ \\
$\mathrm{~B}$ & $1.097 \cdot 10^{-3}$ & $1.058 \cdot 10^{-3}$ & 0.0 \\
$\mathrm{C}$ & $1.052 \cdot 10^{-2}$ & 0.0 & 0.0 \\
$\mathrm{O}$ & $4.322 \cdot 10^{-2}$ & $4.396 \cdot 10^{-2}$ & $4.385 \cdot 10^{-2}$ \\
$\mathrm{Na}$ & $1.310 \cdot 10^{-5}$ & $9.955 \cdot 10^{-4}$ & $1.048 \cdot 10^{-3}$ \\
$\mathrm{Mg}$ & $1.822 \cdot 10^{-4}$ & $1.486 \cdot 10^{-4}$ & $1.486 \cdot 10^{-4}$ \\
$\mathrm{Al}$ & $2.634 \cdot 10^{-4}$ & $2.366 \cdot 10^{-3}$ & $2.389 \cdot 10^{-3}$ \\
$\mathrm{Si}$ & $1.091 \cdot 10^{-3}$ & $1.507 \cdot 10^{-2}$ & $1.580 \cdot 10^{-2}$ \\
$\mathrm{~S}$ & $8.077 \cdot 10^{-5}$ & $5.635 \cdot 10^{-5}$ & $5.635 \cdot 10^{-5}$ \\
$\mathrm{~K}$ & $1.386 \cdot 10^{-5}$ & $6.778 \cdot 10^{-4}$ & $6.932 \cdot 10^{-4}$ \\
$\mathrm{Ca}$ & $1.308 \cdot 10^{-2}$ & $2.975 \cdot 10^{-3}$ & $2.915 \cdot 10^{-3}$ \\
$\mathrm{Fe}$ & $1.499 \cdot 10^{-4}$ & $2.912 \cdot 10^{-4}$ & $3.127 \cdot 10^{-4}$ \\
$\mathrm{Ba}$ & $1.245 \cdot 10^{-4}$ & $1.184 \cdot 10^{-4}$ & 0.0 \\
\hline \hline
\end{tabular}


To determine explicitly the effect of the presence of a neutral beam injector on the activation dose rates two separate calculations were carried out. In the first calculation the test cell with no injector present was considered, and in the second calculation the test cell with an injector present was considered, but in this calculation the radiation sources were the activation photons produced by neutrons that stream through the penetration in the igloo and the activation photons produced inside the igloo that stream through the penetration in the igloo. The first calculation "with no injector" was carried out assuming cylindrical symmetry about the test cell vertical axis as indicated in Fig. 1. It should be noted that in this calculation there are no penetrations through the igloo shield. The second calculation to determine the "injector" contribution was carried out assuming cylindrical symmetry about the injector horizontal axis as indicated in Fig. 1. It should be noted that while the radiation sources used to obtain the injector contribution were obtained taking into account tangential injection the results reported here make the approximation that the injector is oriented radially in the test cell as shown in Fig. 1. Even though the two geometries considered here are very different, the spatial mesh in the two calculations are chosen so that the results of the two calculations in a given spatial region are additive. It should be noted, however, that when the results are added at positions inside the injector an overestimate is obtained because in the calculations "with no injector" the injector components are not present to attenuate the photons. The letters $A$ through $L$ in Fig. 1 give the positions at which dose rate results are presented in Section 3. The arrow with the letters indicate the spatial intervals over which the dose rates are averaged. 


\section{B Calculational Procedure}

Let $\phi(\vec{r}, E, t)$ be the omnidirectional neutron flux per unit energy at the spatial position $\vec{r}$, energy $E$, and time $t$ for either of the two geometries considered. If it is assumed that all neutron transport takes place in times that are negligible compared to times of interest then

$$
\phi(\vec{r}, E, t)=\phi(\vec{r}, E) S(t)
$$

where

$$
\begin{aligned}
\phi(\vec{r}, E)= & \text { the steady-state omnidirectional neutron flux } \\
& \text { per unit energy per unit source strength at } \\
& \vec{r} \text { and } E, \\
S(t)= & \text { the neutron source strength as a function of time. }
\end{aligned}
$$

The energy, angle, and spatial dependence of the source is taken into account in the calculation of $\phi(\vec{r}, E)$. The function $S(t)$ is determined by the number of neutrons produced during a D-T pulse and the repetition rate of $D-T$ pulses. The production rate, $P(\vec{r}, t)$, of nuclei of type $k$ at $\vec{r}$ and $t$ by neutrons may be written

$$
\begin{gathered}
P_{k}(\vec{r}, t)=P_{k}(\vec{r}) S(t) \\
P_{k}(\vec{r})=\sum_{j} n_{j}(\vec{r}) \int_{E_{j k}}^{E_{\max }} d E \phi(\vec{r}, E) \sigma_{j k}(E) .
\end{gathered}
$$


where

$$
\begin{aligned}
E_{j k}= & \text { the threshold for the production of a nucleus of type } \\
& k \text { from nuclei of type } j \text { by a neutron, } \\
E_{\max }= & \text { the maximum energy of any neutron in the system, } \\
\sigma_{j k}(E)= & \text { the microscopic cross section for the production of a } \\
& \text { nucleus of type } k \text { by the interaction of a neutron at } \\
& \text { energy } E \text { with a nucleus of type } j, \\
n_{j}(\vec{r})= & \text { the number of nuclei per unit volume of type } j \text { at } r .
\end{aligned}
$$

Nuclei of type $k$ may or may not be radioactive and produce photons. Furthermore, in addition to the production rates given by Eqs. (2) and (3), a nucleus of type $k$ may also be produced by the decay of other radioactive nuclei. Nuclei of type $k$ may also be destroyed by interaction with neutrons. This destruction is small at the neutron fluxes considered here and is neglected in obtaining the results reported here. If a subscript $l$ is used to denote a particular type of radioactive nuclei that decays with the decay constant $\lambda_{l}$ and if furthermore, it is assumed that the nucleus $l$ is also produced by the decay of nucleus $\ell+l$, then the number per unit volume, $Q_{\ell}$ at $\vec{r}$ and $t$ must satisfy the equation

$$
\begin{aligned}
\frac{d Q_{\ell}(\vec{r}, t)}{d t}= & -\lambda_{\ell} Q_{\ell}(\vec{r}, t)+\lambda_{\ell+1} Q_{\ell+1}(\vec{r}, t) \\
& +P_{\ell}(\vec{r}) S(t) .
\end{aligned}
$$

It is convenient to introduce the substitution

$$
Q_{\ell}(\vec{r}, t)=P_{\ell}^{\prime}(\vec{r}) R_{\ell O}(t)+P_{\ell+1}(\vec{r}) R_{\ell T}(t)
$$




$$
Q_{\ell+1}(\vec{r}, t)=P_{\ell+1}(\vec{r}) R_{\ell+1,0}(t),
$$

and then

$$
\begin{gathered}
\frac{d R_{\ell O}(t)}{d t}=-\lambda_{\ell} R_{\ell O}(t)+S(t) \\
\frac{d R_{\ell J}(t)}{d t}=-\lambda_{\ell} R_{\ell I}(t)+\lambda_{\ell+1} R_{\ell+1,0}(t),
\end{gathered}
$$

that is, with the use of Eqs. (5) and (6) the spatial and time-dependence of $Q_{\ell}(\vec{r}, t)$ may be separated. In writing Eq. (6) it has been assumed, for simplicity, that the $\ell+1$ nucleus is not produced by the decay of a heavier nucleus. The extension to the more general case is straightforward. Equations (7) and (8) are first order differential equations whose solution for any function $S(t)$ may easily be obtained. The solutions are somewhat lengthy and will not be given here, but they are given in detail in Ref. 6.

The production rate of photons may be written

$$
\begin{aligned}
S\left(\vec{r}, E_{\gamma}, t\right) & =\sum_{l} \lambda_{\ell} Q_{\ell}(\vec{r}, t) \Gamma_{\ell}\left(E_{\gamma}\right) \\
& =\sum_{\ell} \lambda_{\ell} \sum_{j=0}^{2} R_{\ell j}(t) P_{\ell+j}(\vec{r}) \Gamma_{\ell}\left(E_{\gamma}\right)
\end{aligned}
$$

where

$$
\begin{aligned}
S_{\gamma}\left(\vec{r}, E_{\gamma}, t\right)= & \text { the number of photons produced per unit volume per } \\
& \text { unit energy at } \vec{r}, E_{\gamma}, \text { and } t \text { by the decay of all nuclei } \\
& \text { at } \vec{r} \text { and } t,
\end{aligned}
$$




$$
\begin{aligned}
\Gamma_{\ell}\left(E_{\gamma}\right)= & \text { the number of photons per unit energy per decay emitted } \\
& \text { at } E_{\gamma} \text { by nuclei of type } \ell .
\end{aligned}
$$

and the photon dose rate at $\vec{r}$ and $t$ can, neglecting the time of photon transport be expressed as

$$
\begin{aligned}
D(\vec{r}, t)= & \int d_{\gamma} C\left(E_{\gamma}\right) \int d \vec{r}^{\prime} d E_{\gamma}^{\prime} \\
& \cdot S\left(\vec{r}^{\prime}, E_{\gamma}^{\prime}, t\right) V\left(\vec{r}, E_{\gamma^{\prime}} ; \vec{r}^{\prime}, E_{\gamma}^{\prime}\right)
\end{aligned}
$$

where

$$
\begin{aligned}
D(\vec{r}, t)= & \text { the photon dose rate at } \vec{r} \text { and } t, \\
C\left(E_{\gamma}\right)= & \text { the photon flux-to-dose rate conversion factor for } \\
& \text { photons with energy } E_{\gamma}, \\
V\left(\vec{r}, E_{\gamma} ; r^{\prime}, E_{\gamma}^{\prime}\right)= & \text { the value function for the photon flux; i.e., the photon } \\
& \text { flux per unit energy at } \vec{r} \text { and } E_{\gamma} \text { due to one photon per } \\
& \text { unit time leaving } \vec{r}^{\prime} \text { with energy } E_{\gamma}^{\prime} .
\end{aligned}
$$

In Eq. (9) the summation over $j$ contains only three terms because no additional terms occurred in the calculations reported here, that is, only parents, daughters and granddaughters were found to occur. Using Eq. (9), Eq. (10) may be put in the form

$$
\begin{aligned}
D(\vec{r}, t)= & \sum_{\ell} \sum_{j=0}^{2} \lambda_{l^{R}} \ell_{l j}(t)\left\{\int \mathrm{dE}_{\gamma} c\left(E_{\gamma}\right)\right. \\
& \cdot \int \mathrm{d} \vec{r}^{\prime} d E_{\gamma}^{\prime} P_{\ell+j}\left(\vec{r}^{\prime}\right) \Gamma_{\ell}\left(E_{\gamma}^{\prime}\right) V\left(\vec{r}, E_{\gamma} ; \vec{r}^{\prime}, E_{\gamma}^{\prime}\right)
\end{aligned}
$$


In Eq. (11) the bracketed quantity is time-independent and contains all of the information that must be obtained from photon transport calculations. If for a given $\vec{r}$ the bracketed quantity is calculated separately for each value of $\ell$ and $j$ then the time-dependence for an arbitrary source strength, $S(t)$, may easily be introduced. Since the individual terms in Eq. (11) are the contribution to the dose rate from a given residual nuclei this procedure also enables one to determine which residual nuclei are contributing significantly to the doser rate at given $\dot{r}$. The timeindependent quantity in each term in the sum in Eq. (11) can be calculated in several ways, but it is very convenient to use Monte Carlo methods because photons are tracked from birth-to-death and thus if a photon contributes to the dose rate at a position $\vec{r}$ it is possible to know the type of residual that gave rise to this photon. ${ }^{6}$ This is the procedure followed in carrying out the calculations reported here.

It is still necessary to consider the activation photons that are produced inside the igloo and stream through the penetration in the igloo into the injector. This photon source for the injector calculation was obtained from the photon flux inside the igloo that existed in the calculations with no injector. The energy, angular and spatial distribution of the outgoing photons at the inside surface of the igloo in the vicinity of the penetration but with no penetration through the igloo was calculated. The direction cosines of these photons were then changed to correspond to tangential injection and these photons were then transported using Monte Carlo methods through the penetration in the igloo into the injector. To account for edge effects, i.e., to account for the fact that photons may travel some distance through the igloo concrete before 
entering the penetration, the photon source inside the igloo was taken over an area that was four times the area of the actual penetration. In the Monte Carlo calculations, the photon flux per unit energy was determined from boundary crossings and thus the dose rates averaged over a particular spatial region rather than at a point were obtained.

\section{C Nuclear Data}

The activation cross sections were taken primarily from the compilation of D. W. Muir ${ }^{7}$, but a few cross sections from ENDF/B-IV ${ }^{8}$ were used. In those cases where a produced radioactive nucleus has a metastable state with a half-life that is substantially different from that of the ground state it was arbitrarily assumed that half of the production is to the ground state and half of the production is to the metastable state, since the experimental data giving the production into the separate states are not generally available. This assumption is crude, but since the individual contributions to the dose rates are known at the end of the calculation it is possible to determine if the assumption has any effect on the final results. Sixty-five residual nuclei with half-lives between $10 \mathrm{~min}$. and 50 years were considered in the calculations. The half-life and photon spectra from each nucleus considered were obtained from the Evaluated Nuclear Structure،Data Files that are available from the Nuclear Data Project at the Oak Ridge National Laboratory. ${ }^{9}$ The photon transport calculations were performed with the Monte Carlo code MORSE ${ }^{10}$ using cross section data processed by D. M. Plaster et al. ${ }^{11}$ The photon fluxes were converted to dose equivalent rates using the flux-to-dose equivalent rate conversion factors of Claiborne and Trubey. ${ }^{12}$ 


\section{RESULTS AND DISCUSSION}

The TFTR pulse length is taken to be $0.5 \mathrm{sec}$ and the time between pulses is taken to be $300 \mathrm{sec}$. The total neutron source strength was assumed to be $7 \cdot 10^{18}$ neutrons/sec. Calculations have been carried out for 100 consecutive pulses in a day, for 100 consecutive pulses each day for 10 consecutive days, and for 100 consecutive pulses each day for 10 days of operation with 40 days between each day of operation. * The results for these three cases are given in Tables 2-4, respectively, for times after shutdown, i.e., for times after the last pulse on the last day of operation, of 1 hour, 1 day, and 7 days. The positions $A$ to $J$ at which the dose rates are presented are those given in Fig. 1. For each of the times considered in the tables, results are given separately for the test cell with no injector and for the injector contribution as explained in Section 2.A. The error on each of the entries in the tables is the statistical error - one standard deviation - expressed in percent. By comparing the corresponding entries in the three tables it can be seen that there is a marked similarity in the results for all of the cases considered. The results with no injector presented here are: not directly comparable with those of Ref. 4 because the concrete compositions used here are not the same as those used in Ref. 4, but qualitatively the results are similar. The dose rates at a given position in Table 3 are generally higher than those in either Table 2 or Table 4, but

\footnotetext{
"These pulse sequences were suggested by $G$. Sheffield as being those of most interest to the TFTR designers.
} 
TABLE 2

DOSE RATE Aí VARIOUS POSITIONS IN THE TEST CELL VS TIME AFTER THE LAST PULSE

100 Pulses in One Day

Pulse Length $=.5 \mathrm{sec}$

Time Between Pulses $=5$ Minutes

Dose Equivalent Rate $(\mathrm{mrem} / \mathrm{h})$

\begin{tabular}{|c|c|c|c|c|c|c|}
\hline \multirow[b]{2}{*}{ Position* } & \multicolumn{2}{|c|}{ 1. Hour After Last Pulse } & \multicolumn{2}{|c|}{1 Day After Last Pulse } & \multicolumn{2}{|c|}{1 Week After Last Pulse } \\
\hline & $\begin{array}{c}\text { Test Cell } \\
\text { Without Injector }\end{array}$ & $\begin{array}{l}\text { Injector } \\
\text { Contribution }\end{array}$ & $\begin{array}{l}\text { Test Cell } \\
\text { Without Injector }\end{array}$ & $\begin{array}{l}\text { Injector } \\
\text { Contribution }\end{array}$ & $\begin{array}{l}\text { Test Cell } \\
\text { Without Injector }\end{array}$ & $\begin{array}{l}\text { Injector } \\
\text { Contribution }\end{array}$ \\
\hline A & $1.5 \cdot 10^{2} \pm 11$ & $7.8 \cdot 10^{-3} \pm 19$ & $2.9 \cdot 10^{1} \pm 14$ & $2.6 \cdot 10^{-3} \pm 20$ & $2.1 \cdot 10^{-1} \pm 10$ & $5.7 \cdot 10^{-6} \pm 20$ \\
\hline B & $5.2 \cdot 10^{1} \pm 10$ & $8.5 \cdot 10^{-2} \pm 40$ & $1.1 \cdot 10^{1} \pm 14$ & $8.4 \cdot 10^{-3} \pm 23$ & $6.6 \cdot 10^{-2} \pm 7$ & $5.1 \cdot 10^{-5} \pm 27$ \\
\hline c & $5.0 \cdot 10^{1} \pm 17$ & $1.6 \cdot 10^{\circ}=17$ & $1.0 \cdot 10^{1} \pm 16$ & $2.8 \cdot 10^{-2} \pm 12$ & $6.8 \cdot 10^{-2} \pm 10$ & $1.2 \cdot 10^{-3} \pm 27$ \\
\hline 0 & $4.7 \cdot 10^{1} \pm 16$ & $2.6 \cdot 10^{2} \div 7$ & $1.2 \cdot 10^{1} \pm 24$ & $7.4 \cdot 10^{0} \pm 28$ & $8.9 \cdot 10^{-2} \pm 12$ & $3.4 \cdot 10^{-1} \pm 4$ \\
\hline E & $7.6 \cdot 10^{1} \pm 11$ & $1.7 \cdot 10^{1}=17$ & $1.4 \cdot 10^{1} \pm 15$ & $6.8 \cdot 10^{-1} \pm 44$ & $1.7 \cdot 10^{-1} \pm 7$ & $2.6 \cdot 10^{-2} \pm 9$ \\
\hline $\mathrm{F}$ & $4.2 \cdot 10^{1} \pm 17$ & $1.8 \cdot 10^{2}=8$ & $8.8 \cdot 10^{0} \pm 23$ & $2.3 \cdot 10^{0} \pm 8$ & $9.3 \cdot 10^{-2} \pm 17$ & $2.3 \cdot 10^{-1} \pm 4$ \\
\hline G & $2.2 \cdot 10^{1} \pm 19$ & $4.6 \cdot 10^{1}=4$ & $6.0 \cdot 10^{0} \pm 18$ & $4.2 \cdot 10^{-1} \pm 4$ & $4.1 \cdot 10^{-2} \pm 19$ & $7.2 \cdot 10^{-2} \pm 1$ \\
\hline$H$ & $2.6 \cdot 10^{1} \pm 26$ & $4.6 \cdot 10^{-}- \pm 9$ & $6.9 \cdot 10^{0} \pm 28$ & $8.3 \cdot 10^{-2} \pm 9$ & $3.4 \cdot 10^{-2} \pm 24$ & $9.2 \cdot 10^{-4} \pm 8$ \\
\hline I & $1.5 \cdot 10^{1} \pm 14$ & $1.4 \cdot 10^{-}: \pm 87$ & $3.5 \cdot 10^{0} \pm 14$ & $4.6 \cdot 10^{-2} \pm 90$ & $2.9 \cdot 10^{-2} \pm 45$ & $7.9 \cdot 10^{-5} \pm 65$ \\
\hline $\mathrm{J}$ & $3.6 \cdot 10^{-3} \pm 31$ & $9.2 \cdot 10^{-4} \pm 17$ & $1.2 \cdot 10^{-3} \pm 32$ & $3.2 \cdot 10^{-4} \pm 17$ & $7.8 \cdot 10^{-6} \pm 27$ & $4.1 \cdot 10^{-7} \pm 17$ \\
\hline$k$ & $5.5 \cdot 10^{-2} \pm 13$ & $8.2 \cdot 10^{-4} \pm 21$ & $1.9 \cdot 10^{-2} \pm 13$ & $2.8 \cdot 10^{-4} \pm 21$ & $2.7 \cdot 10^{-5} \pm 12$ & $3.9 \cdot 10^{-7} \pm 19$ \\
\hline$L$ & $8.2 \cdot 10^{-3} \pm 30$ & $2.4 \cdot 10^{-3} \pm 14$ & $2.7 \cdot 10^{-3} \pm 29$ & $8.2 \cdot 10^{-4} \pm 14$ & $3.1 \cdot 10^{-6} \pm 21$ & $1.1 \cdot 10^{-6} \pm 14$ \\
\hline
\end{tabular}

'see Fig. 1 
TABLE 3

DOSE RATE f.T VARIOUS POSI-IONS IN THE TEST CELL VS TIME AFTER THE LAST PULSE.

1000 Pulses

100 Pulses on Each of Ten Consecutive Days

Pulse Length $=.5 \mathrm{sec}$

Time Between Pulses $=5$ Minutes

Dose Equivalent Rate $(\mathrm{mrem} / \mathrm{h})$

\begin{tabular}{|c|c|c|c|c|c|c|}
\hline \multirow[b]{2}{*}{ Position* } & \multicolumn{2}{|c|}{ I Hour Aiter Last Pulse } & \multicolumn{2}{|c|}{1 Day After Last Pulse } & \multicolumn{2}{|c|}{1 Wee' After Last Pulse } \\
\hline & $\begin{array}{c}\text { Test Cel: } \\
\text { Without Injectcr }\end{array}$ & $\begin{array}{l}\text { Injecter } \\
\text { Contribution }\end{array}$ & $\begin{array}{l}\text { Test Cell } \\
\text { Without Injector }\end{array}$ & $\begin{array}{l}\text { Injector } \\
\text { Contribution }\end{array}$ & $\begin{aligned} & \text { Test } \text { Eel1 } \\
& \text { Without Injectar }\end{aligned}$ & $\begin{array}{l}\text { Injector } \\
\text { Contribution }\end{array}$ \\
\hline$A$ & $1.9 \cdot 10^{2} \pm 11$ & $1.1 \cdot 10^{--2} \pm 20$ & $4.7 \cdot 10^{1} \pm 14$ & $3.8 \cdot 10^{-3} \pm 20$ & $8.8 \cdot 1 C^{-1} \pm 11$ & $2.4 \cdot 10^{-5} \pm 29$ \\
\hline B & $6.8 \cdot 10^{1} \pm 17$ & $\subseteq \cdot 7 \cdot 10^{-2} \pm 34$ & $1.7 \cdot 10^{1} \pm 13$ & $1.3 \cdot 10^{-2} \pm 22$ & $2.8 \cdot 1 \mathrm{C}^{-1} \pm 9$ & $3.9 \cdot 10^{-4} \pm 35$ \\
\hline c & $6.5 \cdot 10^{1} \pm 15$ & $1.6 \cdot 10^{6} \pm 17$ & $1.6 \cdot 10^{1} \pm 15$ & $5.1 \cdot 10^{-2} \pm 10$ & $3.2 \cdot 1 C^{-1} \pm 12$ & $1.0 \cdot 10^{-2} \pm 30$ \\
\hline D & $6.5 \cdot 10^{1} \pm 17$ & $\hat{c} \cdot 8 \cdot 10^{-} \pm 7$ & $1.9 \cdot 10^{1} \pm 22$ & $1.3 \cdot 10^{1} \pm 22$ & $4.4 \cdot 1 \mathrm{C}^{-1} \pm 18$ & $2.7 \cdot 10^{0} \pm 5$ \\
\hline E & $9.9 \cdot 10^{1} \pm 1 i$ & $1.8 \cdot 10_{ \pm 17}^{ \pm 17}$ & $2.4 \cdot 10^{1} \pm 14$ & $1.2 \cdot 10^{0} \pm 36$ & $7.7: 10^{-1} \pm 8$ & $2.3 \cdot 10^{-1} \pm 9$ \\
\hline $\mathrm{F}$ & $5.6 \cdot 10^{1} \pm 17$ & 1. $9.10 \div \pm 8$ & $1.4 \cdot 10^{1} \pm 22$ & $5.3 \cdot 10^{0} \pm 4$ & $4.5 \cdot 10^{-1} \pm 18$ & $1.9 \cdot 10^{0} \pm 5$ \\
\hline G & $3.1 \cdot 10^{1} \pm 17$ & $4.7 \cdot 10^{1} \pm 4$ & $9.5 \cdot 10^{0} \pm 16$ & $1.3 \cdot 10^{0} \pm 2$ & $1.7 \cdot 10^{-1} 24$ & $5.9 \cdot 10^{-1} \pm 1$ \\
\hline$H$ & $3.6 \cdot 10^{1} \pm 26$ & $5.9 \cdot 10^{-1} \pm 9$ & $1.1 \cdot 10^{1} \pm 28$ & $1.4 \cdot 10^{-1} \pm 8$ & $1.4 \cdot 1 \sigma^{-1} \pm 27$ & $4.2 \cdot 10^{-3} \pm 17$ \\
\hline I & $2.0 \cdot 10^{1} \pm 13$ & $2.0 \cdot 10^{-1} \pm 88$ & $5.6 \cdot 10^{0} \pm 15$ & $6.8 \cdot 10^{-2} \pm 90$ & $1.3 \cdot 10^{-1} \pm 50$ & $1.8 \cdot 10^{-4} \pm 43$ \\
\hline J & $5.3 \cdot 10^{-3} \pm 31$ & $11.4 \cdot 13^{-3} \pm 17$ & $1.8 \cdot 0^{-3} \pm 32$ & $4.7 \cdot 10^{-4} \pm 17$ & $5.0 \cdot 10^{-6} \pm 20$ & $7.6 \cdot 10^{-7} \pm 15$ \\
\hline k & $8.2 \cdot 10^{-2} \pm 13$ & $1.2 \cdot 13^{-3} \pm 21$ & $2.3 \cdot 10^{-2} \pm 13$ & $4.2 \cdot 10^{-4} \pm 21$ & $6.4 \cdot 10^{-5} \pm 10$ & $9.0 \cdot 10^{-7} \pm 13$ \\
\hline L & $1.2 \cdot 10^{-2} \pm 29$ & $\Xi .6 \cdot 10^{-3} \pm 14$ & $3.9 \cdot 0^{-3} \pm 28$ & $1.2 \cdot 10^{-3} \pm 15$ & $6.4 \cdot 10^{-6} \pm 26$ & $1.9 \cdot 10^{-6} \pm 12$ \\
\hline
\end{tabular}

`see Fig. 1 
TABLE 4

DOSE RATE AT VARIOUS POSITIONS IN THE TEST CELL VS TIME AFTER THE LAST PULSE

$$
1000 \text { Pulses }
$$

100 Pulses in Each Day of Operation

40 Days Between Days of Operation

Pulse Length $=.5 \mathrm{sec}$

Time Between Pulses $=5$ Minutes

Dose Equivalent Rate (mrem/h)

\begin{tabular}{|c|c|c|c|c|c|c|c|}
\hline \multirow[b]{2}{*}{ Position* } & \multicolumn{2}{|c|}{1 Hour After Last Pulse } & \multicolumn{2}{|c|}{1 Day After Last Pulse } & \multicolumn{2}{|c|}{ I Week After Last Pulse } & \\
\hline & $\begin{aligned} \text { Test Cell } \\
\text { Without Injector }\end{aligned}$ & $\begin{array}{l}\text { Injector } \\
\text { Contrijution }\end{array}$ & $\begin{aligned} \text { Test Cell } \\
\text { Without Injector }\end{aligned}$ & $\begin{array}{l}\text { Injector } \\
\text { Contribution }\end{array}$ & $\begin{array}{l}\text { Test Cell } \\
\text { Without Injector }\end{array}$ & $\begin{array}{l}\text { Injector } \\
\text { Contribution }\end{array}$ & \\
\hline$A$ & $1.5 \cdot 10^{2} \pm 11$ & $7.8 \cdot 10^{-3} \pm 19$ & $2.9 \cdot 10^{1} \pm 14$ & $2.6 \cdot 10^{-3} \pm 20$ & $2.3 \cdot 10^{-1} \pm 10$ & $8.3 \cdot 10^{-6} \pm 25$ & * \\
\hline $\mathrm{B}$ & $5.2 \cdot 10^{1} \pm 10$ & $8.5 \cdot 10^{-2} \pm 40$ & $1.1 \cdot 10^{1} \pm 14$ & $8.5 \cdot 10^{-3} \pm 23$ & $7.1 \cdot 10^{-2} \pm 6$ & $1.5 \cdot 10^{-4} \pm 33$ & \\
\hline C & $5.0 \cdot 10^{1} \pm 17$ & $1.6 \cdot 10^{0} \pm 17$ & $1.0 \cdot 10^{1} \pm 16$ & $3.0 \cdot 10^{-2} \pm 11$ & $7.3 \cdot 10^{-2} \pm 10$ & $3.2 \cdot 10^{-3} \pm 30$ & \\
\hline $\mathrm{D}$ & $4.7 \cdot 10^{1} \pm 16$ & $2.6 \cdot 10^{2} \pm 7$ & $1.2 \cdot 10^{1} \pm 23$ & $8.1 \cdot 10^{0} \pm 26$ & $1.2 \cdot 10^{-1} \pm 19$ & $9.2 \cdot 10^{-1} \pm 5$ & $\cdot$ \\
\hline$E$ & $7.6 \cdot 10^{1} \pm 11$ & $1.7 \cdot 10^{1} \pm 17$ & $1.4 \cdot 10^{1} \pm 15$ & $7.3 \cdot 10^{-1} \pm 41$ & $1.9 \cdot 10^{-i} \pm 6$ & $7.9 \cdot 10^{-2} \pm 8$ & \\
\hline$F$ & $4.2 \cdot 10^{1} \pm 17$ & $1.8 \cdot 10^{2} \pm 8$ & $8.8 \cdot 10^{0} \pm 23$ & $2.7 \cdot 10^{0} \pm 7$ & $9.6 \cdot 10^{-2} \pm 16$ & $6.4 \cdot 10^{-1} \pm 4$ & \\
\hline G & $2.2 \cdot 10^{1} \pm 19$ & $4.6 \cdot 10^{1} \pm 4$ & $6.0 \cdot 10^{0} \pm 17$ & $5.6 \cdot 10^{-1} \pm 2$ & $4.5 \cdot 10^{-2} \pm 18$ & $2.0 \cdot 10^{-1} \pm 1$ & \\
\hline $\mathrm{H}$ & $2.6 \cdot 10^{1} \pm 26$ & $4.6 \cdot 10^{-1} \pm 9$ & $6.9 \cdot 10^{0} \pm 28$ & $8.3 \cdot 10^{-2} \pm 9$ & $3.6 \cdot 10^{-2} \pm 22$ & $1.1 \cdot 10^{-.3} \pm 15$ & \\
\hline I & $1.5 \cdot 10^{1} \pm 14$ & $1.4 \cdot 10^{-1} \pm 87$ & $3.5 \cdot 10^{0} \pm 14$ & $4.6 \cdot 10^{-2} \pm 90$ & $3.2 \cdot 10^{-2} \pm 40^{\circ}$ & $8.0 \cdot 10^{-5} \pm 64$ & \\
\hline $\mathrm{J}$ & $3.6 \cdot 10^{-3} \pm 31$ & $9.2 \cdot 10^{-4} \pm 17$ & $1.2 \cdot 10^{-3} \pm 32$ & $3.2 \cdot 10^{-4} \pm 17$ & $2.1 \cdot 10^{-6} \pm 24$ & $4.3 \cdot 10^{-7} \pm 17$ & \\
\hline $\mathrm{K}$ & $5.5 \cdot 10^{-2} \pm 13$ & $8.2 \cdot 10^{-4} \pm 21$ & $1.9 \cdot 10^{-2} \pm 13$ & $2.8 \cdot 10^{-4} \pm 21$ & $3.0 \cdot 10^{-5} 5_{ \pm 11}$ & $4.4 \cdot 10^{-7} \pm 16$ & \\
\hline$L$ & $8.2 \cdot 10^{-3} \pm 30$ & $2.4 \cdot 10^{-3} \pm 14$ & $2.7 \cdot 10^{-3} \pm 29$ & $8.2 \cdot 10^{-4} \pm 14$ & $3.4 \cdot 10^{-6} \pm 20$ & $1.1 \cdot 10^{-6} \pm 14$ & . \\
\hline
\end{tabular}

* See Fig. 1 
never by a large factor. For 1 hour and 1 day after the last pulse the results in Tables 2 and 4 are nearly identical. For 7 days after the last pulse the dose rate in Table 4 at some of the positions considered are larger than those in Table 2, particularly for the injector, indicating the presence of some long-lived isotopes. Since the results in the three cases are very similar the remainder of the discussion will deal with the case of 1000 pulses delivered in 10 days, but it is clear that except for details the discussion below also applies to the other two cases considered.

From Table 3 it may be seen that with no injector present the dose rate at position A, i.e., near the center of the top of the igloo is larger than that at any of the other positions for all of the times considered. On the other hand, the injector contribution is largest at positions $D$ and $F$, i.e., in the vicinity of the front of the injector magnet, for all times considered. The dose rates at positions $\mathrm{J}, \mathrm{K}, \mathrm{L}$, i.e., at positions outside of the test cell wall, are very small as wouldbe expected.

Except at those positions that are inside of the injector, the injector contribution to the activation dose rate is usually small. To better illustrate this the dose rates at positions $A, C, D$, and $H$ for the case considered in Table 3 are plotted in Fig. 2 as a function of time after the last pulse. The dose rates at positions $E$ and $F$ are also of considerable interest but they are shown in Fig. 3 and 4 and will be discussed in conjunction with these figures. It should be noted that while the largest time considered in Tables $2-4$ is 7 days, the curves in Fig. 2 have been extended to 30 days after the last pulse. In Fig. 2 statistical 


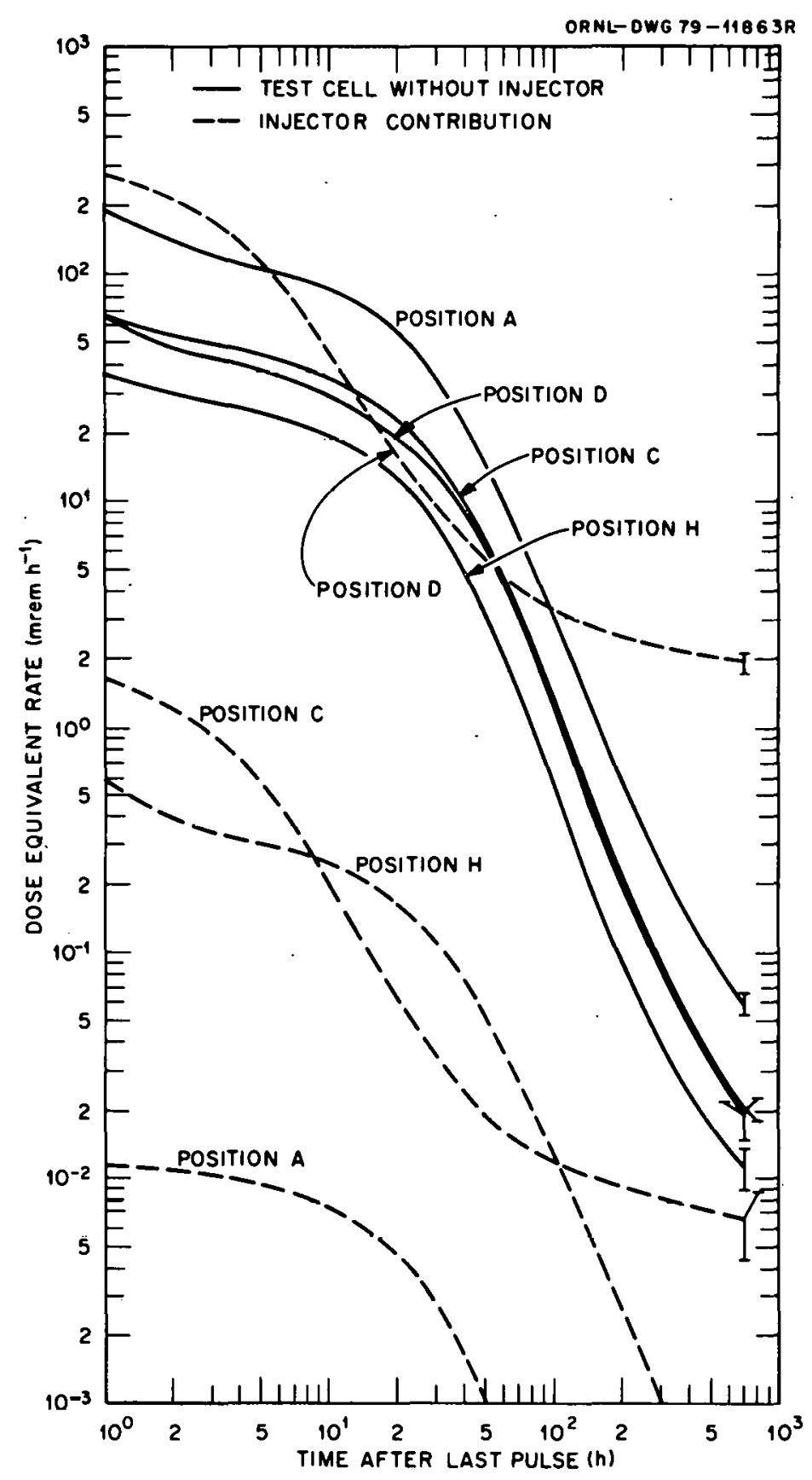

Fig. 2. Dose rate vs time after the last pulse for the case of 1000 pulses delivered at the rate of 100 pulses per day for 10 days. See Fig. 1 for the location of the various positions. 


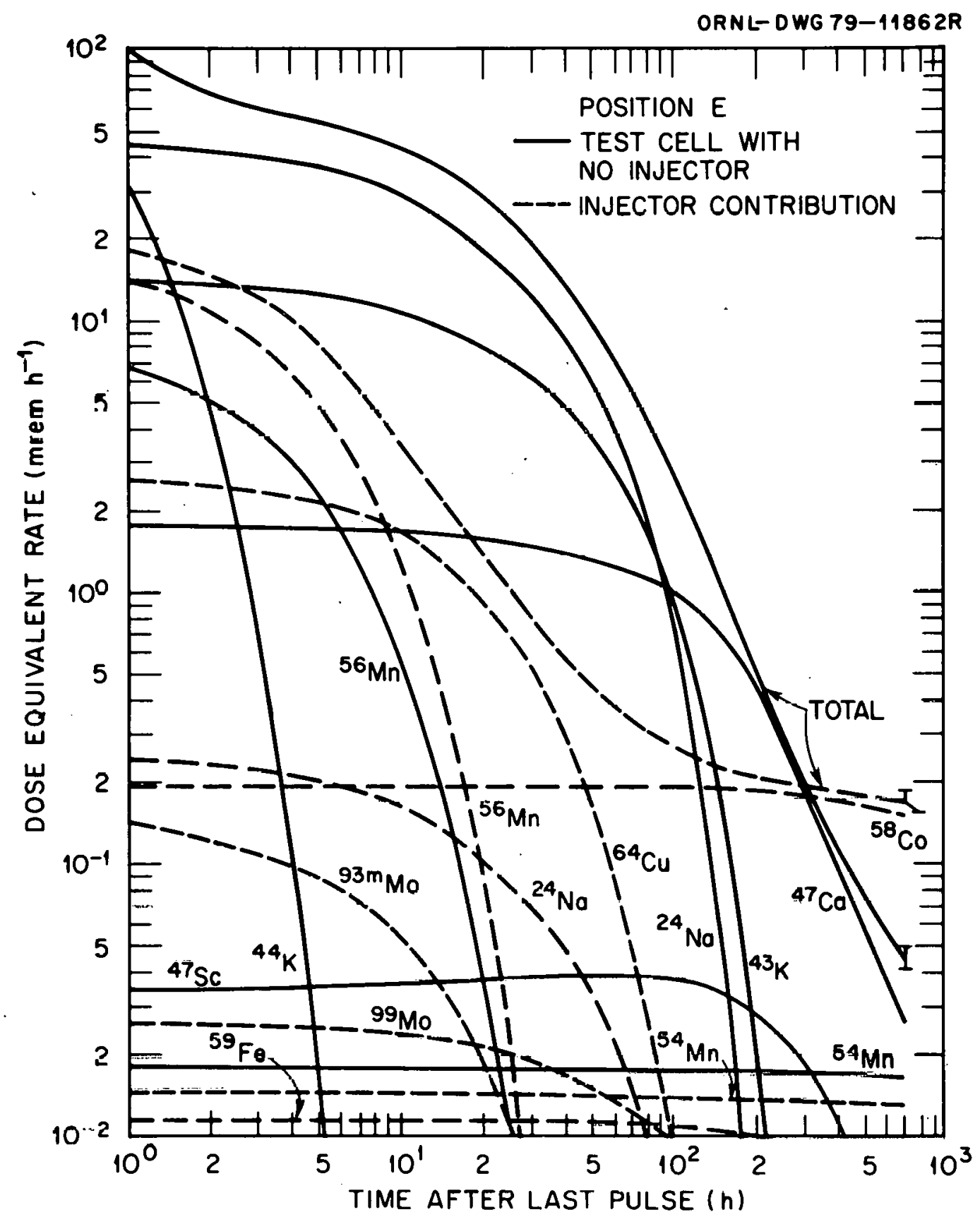

Fig. 3. Dose rate vs time after the last pulse for the case of 1000 pulses delivered at the rate of 100 pulses per day for 10 days. See Fig. 1 for the location of position E. 


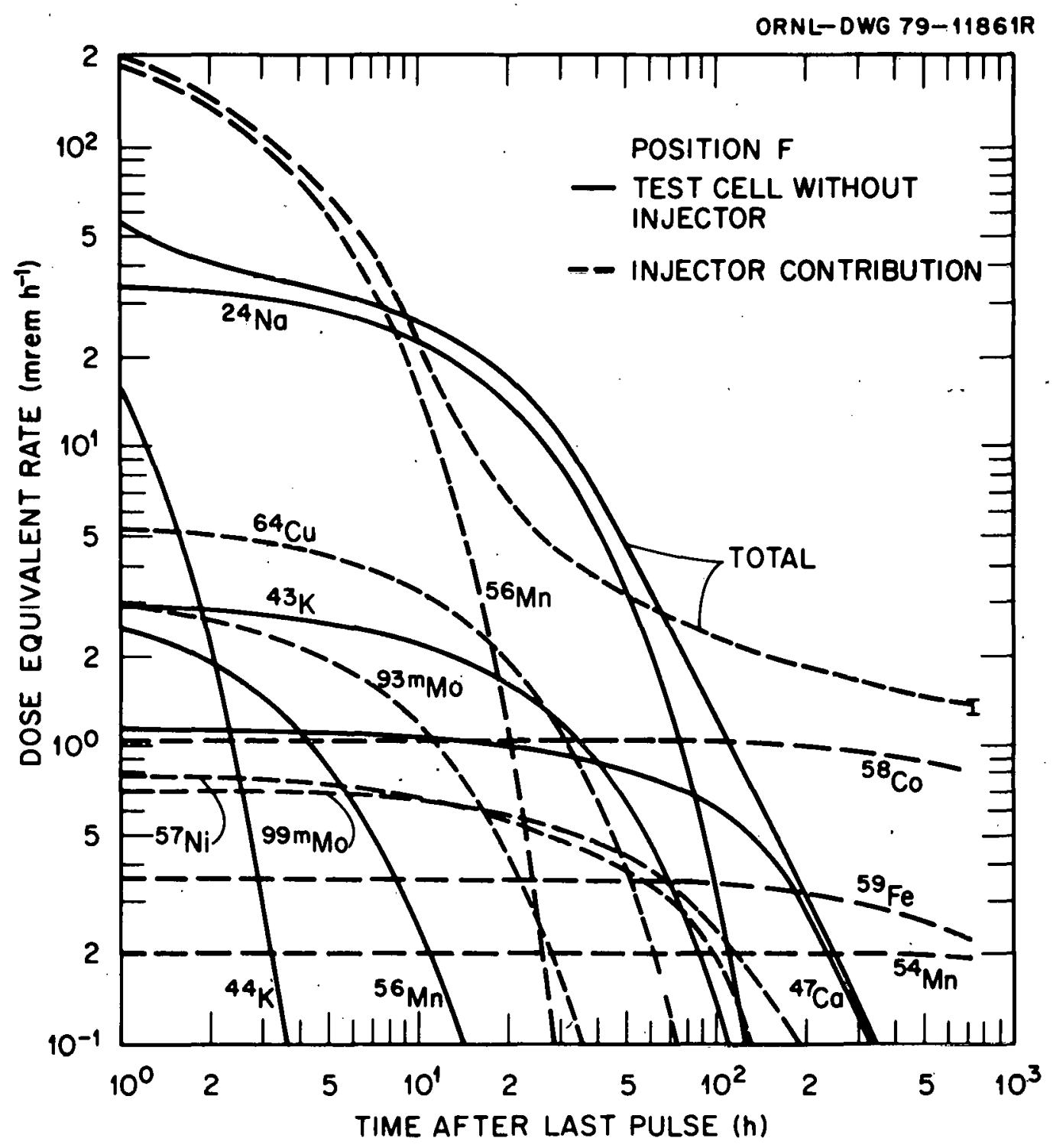

Fig. 4. Dose rate vs time after the last pulse for the case of 1000 pulses delivered at the rate of 100 pulses per day for 10 days. See Fig. 1 for the location of position $F$. 
errors are shown only for the largest time considered since the statistical errors at several of the earlier times are given in Table 3 . It is clear from Fig. 2 that at positions $A, C$, and $H$ the injector contribution is negligible compared to the contribution with no injector.

Position $C$ and $D$ with no injector are very similar and thus the dose rates at these two positions with no injector are very comparable. In fact, the differences shown between the solid curves at position $C$ and $D$ may be due to statistical uncertainty rather than to any actual difference in the dose rates. At position $D$ the injector contribution to the dose rate is considerably larger than the contribution to the dose rate with no injector at the very early times and at the latest times considered. In comparing the solid and dashed curves at position D in Fig. 2 it should be remembered as explained in Section 2. A that inside the injector structure the dose rates with no injector are upper limits.

In Fig. 3 the total dose rates at position $E$ and the contribution to the dose rates from individual nuclei are presented as a function of time after the last pulse. The case considered in Fig. 3 is for 1000 pulses delivered in 10 days, i.e., the same as the case considered in Table 3. The total dose rate for the case with no injector is considerably larger than the dose rate from the injector except at the longest times considered where there is a large contribution to the dose rate from the injector due to $\mathrm{CO}^{58}$. The $\mathrm{CO}^{58}$ comes from the nickel in stainless steel. The tact that there is a significant $\mathrm{CO}^{58}$ contribution at position $E$ from the injector is probably due to the fact that there is streaming path from the stainless steel at the front of the injector to position $E$. The dose rate at position $E$ with no injector is dominated at early times by the $\mathrm{Na}^{24}$ 
contribution and at the latest times considered by the $\mathrm{Ca}^{47}$ and $\mathrm{Mn}^{54}$ contribution. It is of no practical importance but it is interesting to note that the dose rate from $\mathrm{S}_{C} 47$ increases after the neutron beam is turned off because $\mathrm{S}_{C} 47$ is produced by the decay of $\mathrm{Ca}^{47}$. The dose rate from the injector at position $\mathrm{E}$ is dominated by the $\mathrm{Mn} 56$ contribution at early times and by the $\mathrm{Co}^{58}$ contribution at the latest times considered.

In Fig. 4 the total dose rates and the contribution to the dose rates from the various residual nuclei are given as a function of time after the last pulse at position $F$, i.e., on the front face of the injector magnet. For early and late times the injector contribution to the total dose rate is considerably larger than the contribution from the case with no injector but this is not true at intermediate times. The nuclei that contribute significantly to the dose rate at position $F$ both with no injection and from the injector are for the most part the same as those that contributed significantly at position $E$. 


\section{REFERENCES}

1. Tokamak Fusion Test Reactor - Final Design Report, PPPL-1475 (1978).

2. R. T. Santoro et al., "Two- and Three-Dimensional Neutronics Calculations for the TFTR Neutral Beam Injectors," ORNL/TM-6354, Oak Ridge National Laboratory (1978) (to be published in Nuclear Science and Engineering).

3. R. T. Santoro et al., "Shielding Calculations for the TFTR Neutral Beam Injectors," ORNL/TM-6949 Oak Ridge National Laboratory (1979).

4. R. A. Friedenberg, "Construction of Isodose Contour Maps for the TFTR," Trans. Am. Nucl. Soc. 28, 657 (1978).

5. R. G. Alsmiller, Jr. and J. Barish, "Photon Dose Rates From Induced Activity in the Beam Stop of a $400 \mathrm{GeV}$ Proton Accelerator," Nucl. Instr. Methods 155, 399 (1978).

6. J. Barish, T. A. Gabriel and R. G. Alsmiller, Jr., "MAGIK - A Monte Carlo System for Computing Induced Residual Activity Dose Rates," ORNL-5561, Oak Ridge National Laboratory (1979).

7. D. W. Muir, "DLC-33 Data Library MONTAGE," Radiation Shielding Information Center, Oak Ridge National Laboratory (1975).

8. D. J. Garber and C. Brewster, "ENDF/B Cross Sections," BNL-17100 (ENDF-200) Second Edition (1975).

9. W. B. Ewbank, "tvaluáted Nuclear Structure Dala Files (ENsDF) for Basic and Applied Research," Proc. Fifth CODATA Conf. June 28-July 1, 1976; see also D. C. Kocher, W. B. Ewbank and M. J. Martin, "Standardized Radfoactivity Decay Data Sets for Use in Radioactivity Dosimetry," IAEA Symposium on National and International Standardization of Radiation Dosimetry, Atlanta, GA, December 5-9, 1977 : 
10. M. B. Emmett, "The MORSE Monte Carlo Radiation Transport Code System," ORNL -4972, Oak Ridge National Laboratory (1975).

11. D. M. Plaster, R. T. Santoro and W. E. Ford, III, "Coupled 100-Group Neutron and 21-Group Gamma-Ray Cross Sections for EPR Calculations," ORNL/TM-4872, Oak Ridge National Laboratory (1975).

12. H. C. Claiborne and D. K. Trubey, "Gamma Ray Dose Rates in a Slab Phantom," Nucl. Am. Tech. 8,450 (1970). 
THIS PAGE

WAS INTENTIONALLY

LEFT BLANK 
ORNL/TM-6904

Dist. Category UC-20d

(Fusion Systems)

\section{Internal Distribution}

1. L. S. Abbott.

2. F. S. Alsmiller

3-7. R. G. Alsmiller, Jr.

8-12. J. Barish

13-17. J. M. Barnes

18. D. E. Bartine

19. L. A. Berry

20. G. F. Flanagan

21. T. A. Gabriel

22. H. Goldstein (Consultant)

23-27. R. A. Lillie

28. F. C. Maienschein

29. R. W. Peelle

30. RSIC

37-36. R. T. Santoro
37. D. Steiner

38. P. Greebler (Consultant)

39. W. B. Loewenstein (Consultant)

40. R. Wilson (Consultant)

41-42. Central Research Library

43. ORNL Y-12 Technical Library Document Reference Section

44. Laboratory Records Department

45. Laboratory Records - RC

46. ORNL Patent. Office

External Distribution

47. F. E. Coffman, Chief, Systems and Applications Studies Branch, Office of Fusion Energy, Department of Energy, Washington, D.C. 20545

48. W. Cooper, Lawrence Berkeley Laboratory, Neutral Beam Group, Berkeley, CA 94720

49. C. R. Head, Office of Fusion Energy, G-234, Department of Energy, Washington, D.C. 20545

50. H. W. Hendel, Plasma Physics Laboratory, Princeton University, P.0. Boy 451 , Princeton, NJ 08540

51. R. Hensler, Ebasco Services, Inc., 2 Rector St., NY, NY 10006

52. H. J. Hrwe, Jr., Plasma Physics Laboratory, Princeton University, P.0. Box 451, Princeton, NJ 08540

53. R. Little, Plasma Physics Laboratory, Princeton University, P.0. Box 451, Princeton, NJ 08540

54. L. C. Pittenger, Lawrence Livermore Laboratory, P.0. Box 808, L-383, Livermore, CA 94550

55. B. Pritchard, Plasma Physics Laboratory, Princeton University, P.0. Box 451, Princeton, NJ 08540

56-60. M. M. H. Ragheb, Fusion Technology Program, University of Wisconsin, Madison, WI 53706

61. P. J. Reardon, Plasma Physics Laboratory, Princeton University, P.0. Box 451, Princeton, NJ 08540

62. Yasushi Seki, Japan Atomic Energy Research Institute, Tokai-mura, Ibaraki-ken, Japan

63. G. Sheffield, Plasma Physics Laboratory, Princeton University, P.0. Box 451, Princeton, NJ 08540

64. E. Stern, Plasma Physics Laboratory, Princeton University, P.0. Box 451, Princeton, NJ 08540 


\section{External Distribution (Cont'd)}

65. K. Wright, Plasma Physics Laboratory, Princeton University, P.0. Box 451, Princeton, NJ 08540

66. K. Young, Plasma Physics Laboratory, Princeton University, P. 0. Box 451, Princeton, $\mathrm{NJ} 08540$

67. Office of Assistant Manager, Energy Research and Development, DOE-ORO, Oak Ridge, TN 37830

68-218. Given distribution as shown in TID-4500, Magnetic Fusion Energy (Distribution Category UC-20d: Fusion Systems) 